\title{
Growing number of medical trainees named in complaints
}

\author{
— Cite as: CMAJ 2019 June 24;191:E717-8. doi: 10.1503/cmaj.109-5762
}

Posted on cmajnews.com on June 4, 2019.

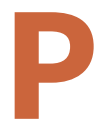

atient complaints against trainee doctors are on the rise across Canada. Some physicians are calling for more training to handle medico-legal issues.

Medical residents and fellows were named in nearly 3000 legal and regulatory matters in the past decade, according to Canadian Medical Protective Association (CMPA). The association has also seen a steady rise in trainees calling for legal advice, with 803 calls in 2017, up from 384 in 2008.

These cases raise important questions for medical schools, said CMPA researcher
Allan McDougall at the 2019 Canadian Conference on Medical Education. "Is that enough to develop a program at your school? Is that enough to embed a lecture? Is your continuing medico-legal education enough?"

Between 2008 and 2017, 854 regulatory complaints involved trainees, representing a $94 \%$ increase in complaints per year. This trend mirrored a $117 \%$ increase in regulatory matters involving other physicians across Canada.

Over the same period, trainees accounted for $11 \%$ of all CMPA legal actions. An analysis of a sample of 320 trainees named in civil legal complaints found that $96 \%$ of cases were related to care provided in hospitals and $58 \%$ of cases took three or more years to resolve. Half of the trainees named in civil legal cases were on call during alleged incidents, and in 119 cases in which trainees were found accountable, half involved allegations of diagnostic errors. The CMPA will release more data on legal matters naming trainees later this year, pending publication.

Growth in complaints doesn't mean an increase in errors or an increase in poor care, McDougall noted. "It's just an increase in being named." Most complaints involving trainees also named other physicians, he said. These data exclude trainees in Quebec, who have a different medicolegal protection system.

Trainees in medical and surgical specialties faced more complaints than those in family medicine. Likely this is due to differences in the length of their training, said McDougall. Medical and surgical specialties with the most complaints included internal medicine, emergency medicine, psychiatry, obstetrics and gynecology, general surgery and orthopedics.

McDougall attributed the rise in complaints to changing expectations and demands. "Trainees are practising in an era of increasing health care complexity."

A survey of 201 physicians presented at the same conference 
found that many doctors lack confidence handling medico-legal issues, including routine tasks like filling out insurance and disability forms.

"Insufficient medico-legal training is provided in North American medical schools, residency programs and thereafter," said survey author Harpreet Pangli, a third-year medical student at the University of British Columbia. "Physicians are often not familiar with the nuances of legal terminology, the legal definitions of medical negligence and the current standards within their specialty."

Of the physicians surveyed, $80 \%$ said they received no medico-legal training in medical school or residency. However, many reported receiving post-residency training, mostly through CMPA programs.

"An overwhelming majority stated that there is further need for more education and training," said Pangli.

Lauren Vogel, CMAJ 